\title{
Bribing in First-Price Auctions: Corrigendum
}

\section{Citation}

Kotowski, Maciej H., and Shiran Rachmilevitch. 2013. Bribing in First-Price Auctions:

Corrigendum. 2013. Games and Economic Behavior, in press.

\section{Published Version}

http://dx.doi.org/10.1016/j.geb.2013.03.008

\section{Permanent link}

http://nrs.harvard.edu/urn-3:HUL.InstRepos:10591649

\section{Terms of Use}

This article was downloaded from Harvard University's DASH repository, and is made available under the terms and conditions applicable to Open Access Policy Articles, as set forth at http:// nrs.harvard.edu/urn-3:HUL.InstRepos:dash.current.terms-of-use\#OAP

\section{Share Your Story}

The Harvard community has made this article openly available.

Please share how this access benefits you. Submit a story.

\section{Accessibility}




\title{
Bribing in First-Price Auctions: Corrigendum
}

\author{
Maciej H. Kotowski* Shiran Rachmilevitch ${ }^{\dagger}$
}

February 15, 2013

\begin{abstract}
We clarify the sufficient condition for a trivial equilibrium to exist in the model of Rachmilevitch (2013).
\end{abstract}

Rachmilevitch (2013), henceforth R13, studies the following game. Two ex ante identical players are about to participate in an independent-private-value first-price, sealed bid auction for one indivisible object. After the risk-neutral players learn their valuations but prior to the actual auction, player 1 can offer a take-it-or-leave-it (TIOLI) bribe to his opponent in exchange for the opponent dropping out of the contest. If the offer is accepted, player 1 is the only bidder and obtains the item for free; otherwise, both players compete non-cooperatively in the auction as usual. This is called the first-price TIOLI game. ${ }^{1}$ R13 shows that under the restriction to continuous and monotonic bribing strategies for player 1, any equilibrium of this game must be trivial - the equilibrium bribing function employed by player 1, if it is continuous and non-decreasing, must be identically zero. In this note, we clarify the sufficient conditions under which a trivial equilibrium exists. These are less stringent than originally proposed.

Let $F$ denote the cumulative distribution function of players' types (valuations). $F$ is atomless, has full support on $[0,1]$, and its density is $f$. The following is Theorem 2 from R13.

Theorem 2. Suppose that $F$ is differentiable and that it satisfies $2 F(t)+t f(t) \geq 1$ for all $t \in(0,1]$, where $f=F^{\prime}$. Then, the first-price TIOLI game has a trivial equilibrium.

\footnotetext{
*Kennedy School of Government, Harvard University. E-mail: <maciej_kotowski@hks.harvard.edu>

$\dagger$ (Corresponding Author) Department of Economics, University of Haifa. E-mail: < shiranrach@gmail.com>, <shiranrach@econ.haifa.ac.il >

${ }^{1}$ See R13 for a detailed description of the game. The inspiration for this game comes from Esô and Schummer (2004), who study a second-price auction preceded by a bribing stage.
} 
An unfortunate fact regarding this theorem is that it is vacuously true.

Claim 1. There does not exist a distribution $F$ such that $2 F(t)+t f(t) \geq 1$ for all $t \in(0,1]$.

Proof. Suppose the contrary and choose $0<\epsilon<1 / 2$. Since $F$ is continuous and $F(0)=0$, there exists $\bar{t}>0$ such that for all $t<\bar{t}, F(t)<\epsilon$. Thus, for all $0<t<\bar{t}, 2 \epsilon+t f(t) \geq 1$. However, this implies that for $t \in(0, \bar{t}), F(t)=\int_{0}^{t} f(x) d x \geq \int_{0}^{t} \frac{1-2 \epsilon}{x} d x=\infty$, which is a contradiction.

Fortunately, Theorem 2's conclusion is true under a relatively weak alternative condition. All that is required is that $F$ is concave. The intuition is that when there is a high probability that bidders have low valuations, player 1 does not find it worthwhile to bribe player 2 . This is the same intuition as initially proposed by $\mathrm{R} 13$.

Theorem 2'. If $F$ is concave, the first-price TIOLI game has a trivial equilibrium.

To prove this theorem we first establish a useful lemma using a geometric argument.

Lemma 1. Suppose $b$ and $x$ are two positive numbers such that $b+x \leq 1$. Then

$$
F(b) x+[F(b+x)-F(b)] b \leq \int_{0}^{b+x} F(t) d t .
$$

Proof. We consider two cases. In case 1 , suppose $0 \leq x \leq b$. We make our argument with reference to Figure 1a. In the figure, $\int_{0}^{b+x} F(t) d t$ is the region below the thick curve, $F(t)$, to the left of $b+x$. The left-hand side of (1), $F(b) x+[F(b+x)-F(b)] b$, equals the shaded region, or $A+B+C+D$. Since $F$ is concave and therefore $F(x) \geq F(b+x)-F(b)$, it easily follows that $Y \geq B$. Thus, it is sufficient to show that $X \geq C$. By concavity of $F, D \geq C$. Finally,

$$
D=\int_{b}^{b+x} F(t)-F(b) d t=\int_{0}^{x} F(t+b)-F(b) d t \leq \int_{0}^{x} F(t) d t=X .
$$

Hence, $X \geq D \geq C$ as required.

For case 2, suppose $0 \leq b \leq x$. The situation is as in Figure 1b. Again it is sufficient to show that $D \leq X$. This inequality follows since

$$
D=\int_{x}^{b+x} F(t)-F(x) d t=\int_{0}^{b} F(x+t)-F(x) d t \leq \int_{0}^{b} F(t) d t=X .
$$




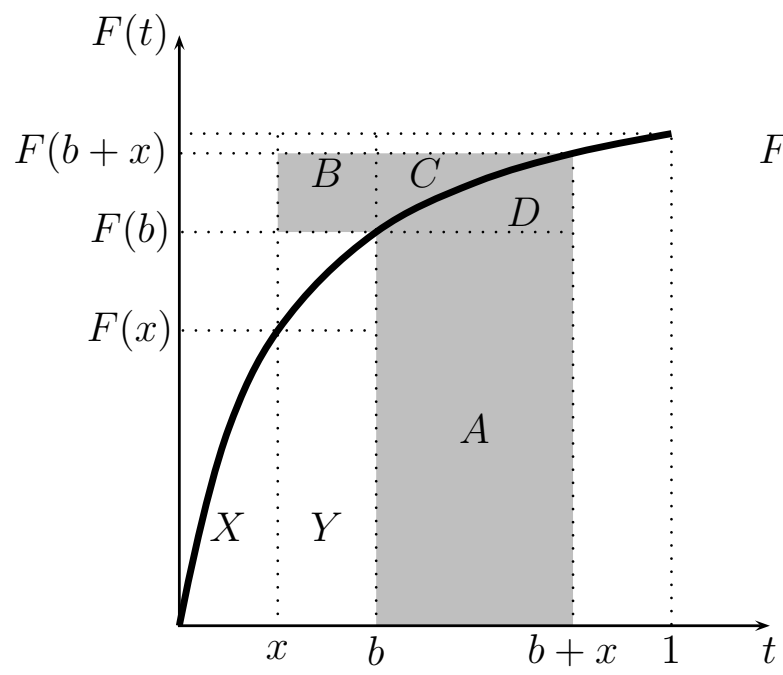

(a) Case 1.

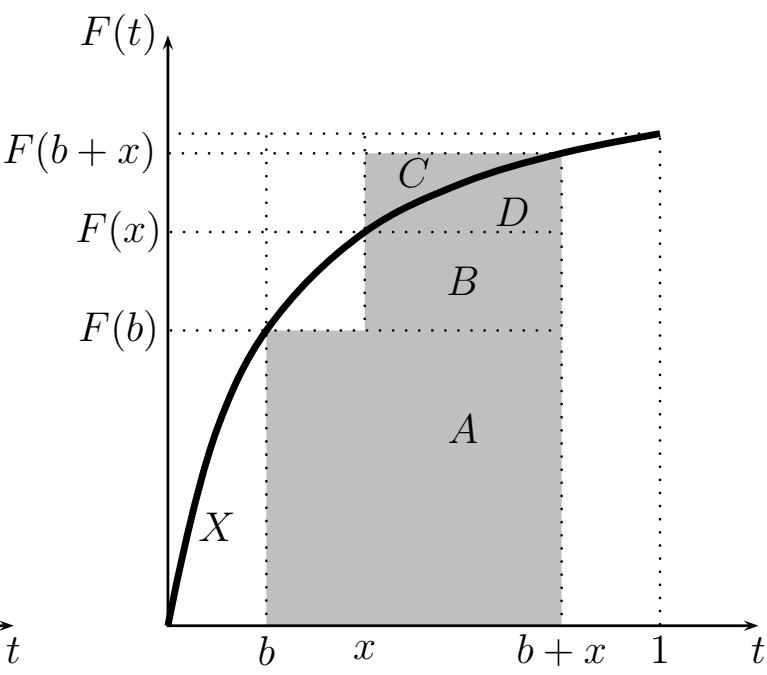

(b) Case 2 .

Figure 1: The geometric argument in Lemma 1. Figures not to scale.

We can now prove Theorem $2^{\prime}$ by adapting the argument from the proof of Theorem 2 in R13.

Proof of Theorem $2^{\prime}$. Consider the following strategy profile. Player 1 offers a bribe of zero independent of his type. If this bribe is rejected, he bids as in the one-shot, symmetric Bayesian Nash equilibrium (BNE) of the first-price auction. Irrespective of type, player 2 rejects a bribe of zero and post-rejection bids as in the symmetric BNE of the auction. Player 2 accepts the bribe of $b>0$ if and only if his valuation $\theta_{2} \leq b$. If player 2 rejects the bribe $b>0$, he believes that player 1 is bidding $\left(\theta_{2}-b\right)$, and he bids $\left(\theta_{2}-b\right)^{+} .^{2}$ In this case, player 1 is prescribed his optimal bid in this post-rejection-of- $b$ information set (it is easy to show that such a best-response exists).

It is sufficient to verify that player 1 does not have a profitable deviation to a strictly positive bribe. Let $b>0$ be the bribe offered by player 1 and let $x$ be player 1 's bid in the auction following the (possible) rejection of $b$ by player 2. Obviously, we can assume that $x \leq 1-b .{ }^{3}$ Given the prescribed (off-equilibrium path) behavior of player 2, the expected

\footnotetext{
${ }^{2}$ The bid $r^{+}$is identical to the bid $r$, except that it wins for sure if the competing bid is $r^{\prime} \leq r$. See R13 for the details.

${ }^{3}$ If player 2 rejects the sure payoff $b$, then optimality dictates that he does not bid more than $\theta_{2}-b$ in the auction; therefore, player 1 has no reason to bid strictly above $1-b$.
} 
payoff of player 1 is

$$
\Pi\left(b, x \mid \theta_{1}\right)=F(b)\left(\theta_{1}-b\right)+[F(b+x)-F(b)]\left(\theta_{1}-x\right) .
$$

On the equilibrium path, the expected payoff of bidder 1 of type $\theta_{1}$ is $\pi\left(\theta_{1}\right)=\int_{0}^{\theta_{1}} F(t) d t$. It is sufficient to verify that for all $\theta_{1}$ and for all $0<b \leq \theta_{1}$ and $0 \leq x \leq 1-b$, it is the case that $\Pi\left(b, x \mid \theta_{1}\right) \leq \pi\left(\theta_{1}\right)$. Let $\psi\left(\theta_{1}\right) \equiv \pi\left(\theta_{1}\right)-\Pi\left(b, x \mid \theta_{1}\right)$. Note that $\psi^{\prime}\left(\theta_{1}\right)=F\left(\theta_{1}\right)-F(b+x)$, so $\psi$ has a minimum at $\theta_{1}=b+x$. Also, $\Pi(b, x \mid b+x)=F(b) x+[F(b+x)-F(b)] b$. By Lemma $1, \psi(b+x) \geq 0$. Therefore, $\psi \geq 0$. Put differently, $\pi\left(\theta_{1}\right)-\Pi\left(b, x \mid \theta_{1}\right) \geq 0$ for all $\theta_{1}$.

\section{References}

Esô, P. and Schummer, J. (2004). Bribing and signaling in second price auctions. Games and Economic Behavior, 47(2):299-324.

Rachmilevitch, S. (2013). Bribing in first-price auctions. Games and Economic Behavior, $77(1): 214-228$. 